\begin{tabular}{|c|c|c|}
\hline & $\begin{array}{c}\text { GEOAMBIENTE ON-LINE } \\
\text { Revista Eletrônica do Curso de Geografia - UFG/REJ } \\
\text { Graduação e Pós-Graduação em Geografia } \\
\text { htpp://www.revistas.ufg.br/geoambiente } \\
\text { Jataí-Go I n } 34 \text { | Maio-Agos/2019 }\end{array}$ & $\begin{array}{c}\text { GEO } \\
\text { G G }\end{array}$ \\
\hline
\end{tabular}

\title{
TASAS DE CAMBIO DE USO DEL SUELO Y AGRICULTURIZACIÓN EN EL PARTIDO DE TANDIL, ARGENTINA
}

\section{Patricia Vazquez ${ }^{1}$, Laura Zulaica $^{2}$, Ailín Somoza ${ }^{1}$}

(1- CONICET, Centro de Estudios Sociales de América Latina (CESAL), Facultad de Ciencias Humanas, Universidad Nacional del Centro de la Provincia de Buenos Aires. Paraje Arroyo Seco s/n, CP 7000 Tandil, Argentina. Email: patriciavazquez@conicet.gov.ar, somoza.ailin@conicet.gov.ar, 2 - CONICET, Instituto del Hábitat y del Ambiente (IHAM), Facultad de Arquitectura, Urbanismo y Diseño (FAUD), Universidad Nacional de Mar del Plata (UNMdP). Funes 3350, CP 7600 Mar del Plata, Argentina, Email: laurazulaica@conicet.gov.ar)

Resumen. El proceso de agriculturización, como caso particular y frecuente de cambio en el uso de la tierra, es uno de los propulsores del Cambio Global y causante de transformaciones ambientales. Los objetivos planteados en este trabajo fueron analizar las tasas de cambio anual en el uso del suelo en el partido de Tandil, entre 1988 y 2015, a fin de caracterizar el proceso de agriculturización en los paisajes que lo componen; determinar los cultivos con mayor incidencia en dicho proceso e identificar los principales servicios ecosistémicos afectados. Metodológicamente se obtuvieron imágenes satelitales, se realizaron clasificaciones supervisadas, se emplearon estadísticas oficiales, estudios antecedentes y relevamientos de campo. Los resultados obtenidos muestran un incremento de la superficie destinada a la agricultura en desmedro de la ganadería con una tasa de cambio anual de 3.28 (especialmente en la Llanura distal) y una alteración en la composición de los principales cultivos. Dicho contexto propicia la provisión de servicios ecosistémicos de abastecimiento y el deterioro de la provisión de servicios de regulación. El análisis de los cambios en el uso del suelo constituye una herramienta útil para tomar dimensión del proceso de agriculturización y los impactos ambientales asociados.

Palabras clave: cambio global; sensores remotos; servicios ecosistémicos.

Artigo recebido para publicação em 22 de Maio de 2019

Artigo aprovado para publicação em 18 de Agosto de 2019 


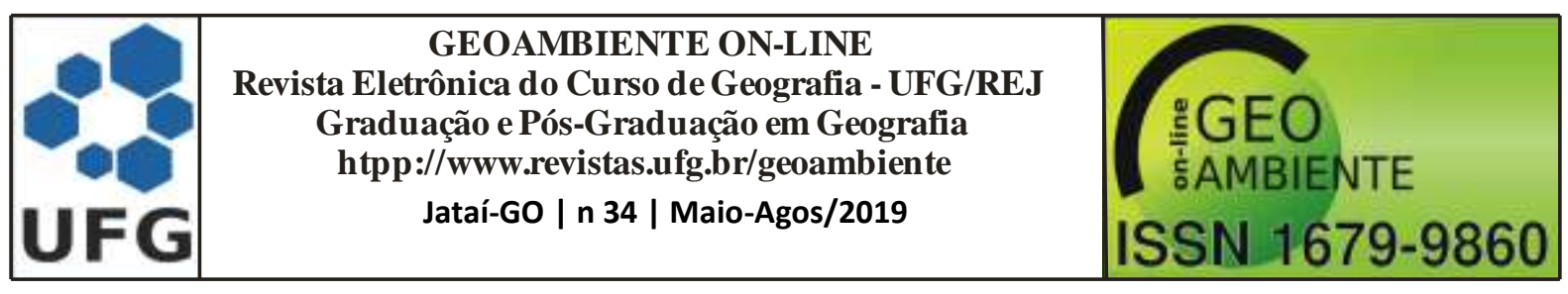

\section{TAXAS DE VARIAÇÃO DO USO DO SOLO E INTENSIFICAÇÃO DA AGRICULTURA NO MUNICÍPIO DE TANDIL, ARGENTINA.}

Resumo. O processo de intensificação agrícola, um caso particular e frequente de variação no uso da terra, é um dos motores da alteração global e causador de transformações ambientais. Os objetivos estabelecidos neste trabalho foram analisar as taxas de variação anual do uso da terra no Tandil, entre 1988 e 2015, a fim de caracterizar o processo de intensificação agrícola nas paisagens que o compõem; determinar os cultivos com maior incidência neste processo e identificar os principais serviços ecossistêmicos afetados. Metodologicamente, foram obtidas imagens de satélite e classificações supervisionadas e foram utilizados estatísticos oficiais, estudos de base e levantamentos de campo. Os resultados obtidos mostram um aumento da superfície destinada à agricultura em detrimento da pecuária com uma taxa de variação anual de 3,28 (especialmente na planície distal) e uma alteração na composição dos principais cultivos. O contexto favorece a prestação de serviços ecossistêmicos de abastecimento e a degradação da prestação de serviços de regulação. A análise das variações no uso da terra é uma ferramenta útil para dimensionar o processo de intensificação agrícola e os impactos ambientais associados.

Palavras-chave: alteração global; serviços ecossistémicos; sensoriamento remoto.

\section{EXCHANGE RATES OF LAND USE AND AGRICULTURIZATION IN THE TANDIL COUNTRY, ARGENTINA.}

Abstract. The agriculturization as particular process of change in the use of land is one of the drivers of the Global Change and consequently it causes environmental transformations. The aims of this work were to analyze the exchange rates annual in the use of land in Tandil department, between 1988 and 2015, in order to characterize the process of agriculturization in the landscapes that compose it; to determine the crops with the highest incidence in this process and to identify the main ecosystem services affected. Methodologically were obtained satellite images and supervised classifications. Also were used official statistics, background studies and field surveys. The results shows an increase in the area intended to agriculture at the expense of livestock with an annual change rate of 3.28 (especially in the distal plain) and an alteration in the composition of the main crops. It is observed how this context favors the supplying services and the deterioration of most of the regulating and cultural services. The 


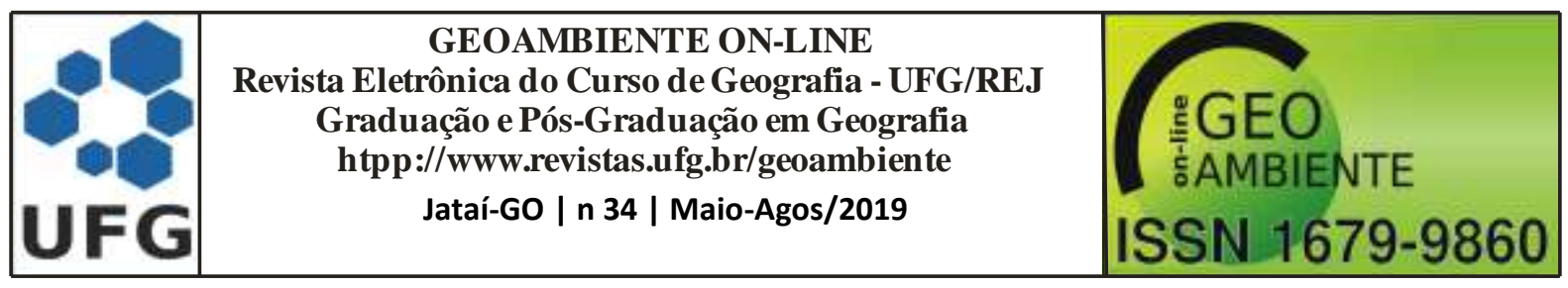

analysis of changes in land use is a useful tool to take dimension of the process of agriculturization and its associated impacts.

Keywords: global change; ecosystem services; remote sensing.

\section{Introducción}

La agricultura en Argentina, y especialmente en la Región Pampeana, enfrenta un proceso de transformación sin precedentes tendiente a un uso intensivo de los recursos naturales (PENGUE, 2014). Los cambios en el uso del suelo y la consecuente alteración de la cobertura vegetal, producidos por esta actividad, forman parte de los principales factores de Cambio Global. Dicho término se encuentra asociado a tres características que provocan que los cambios generados sean singulares. Por un lado, la rapidez con la que los cambios tienen lugar con consecuencias notables en espacios de tiempo tan cortos como décadas; el hombre como única especie motor del cambio; el incremento, apoyado en el desarrollo tecnológico, en el consumo de recursos per cápita por la humanidad (DUARTE et al., 2006).

En la agricultura llevada a cabo en la Región Pampeana Argentina (RPArg) las tres características principales del Cambio Global se encuentran representadas por el proceso de agriculturización. Este proceso es definido como el uso creciente y continuo de las tierras para cultivos agrícolas en lugar de usos ganaderos o mixtos y es asociado en la región pampeana con cambios tecnológicos, intensificación ganadera, expansión de la frontera agropecuaria y desarrollo de producciones orientadas al monocultivo (MANUEL-NAVARRETE, 2006). PARUELO et al. (2006) lo definen como un caso particular, y frecuente, de cambio de uso de la tierra. De hecho, el perfil agroproductivo de la región ha estado caracterizado por una expansión acelerada de la técnica de siembra directa en reemplazo de la labranza convencional, una intensificación de la producción mediante un uso mayor de agroquímicos, la incorporación de cultivos transgénicos y el reciente manejo diferencial por ambientes, también llamado agricultura de precisión (SATORRE Y BERT, 2014).

En el escenario planteado, manifiesto en la Argentina, a medida que aumenta la productividad y rentabilidad inmediata también lo hacen los costos ambientales. Los cambios productivos se traducen en una mayor presión sobre los ecosistemas que conducen a una simplificación estructural y funcional de los sistemas productivos en términos de degradación del suelo, contaminación del agua y del aire, pérdida de diversidad biológica, etc. (PENGUE, 


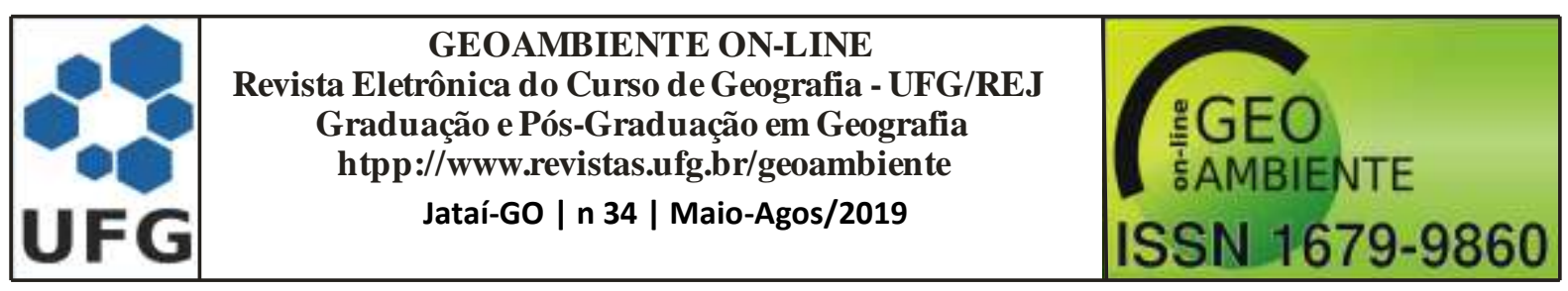

2014). Es así que la actividad agrícola consigue aumentar la productividad y rentabilidad a la vez que aumenta los costos ambientales. De acuerdo a PARUELO et al. (2006) resulta útil para evaluar las consecuencias ambientales de los cambios en el uso de la tierra el concepto de Servicios Ecosistémicos (SE) puesto que su provisión se ve afectada directamente por las modificaciones descriptas.

En este contexto, los estudios sobre el cambio y cobertura del suelo proporcionan la base para conocer las tendencias de diversas problemáticas ambientales asociadas a una región determinada (LAMBIN Y MEYFROIDT, 2010). Particularmente, el análisis de los cambios de uso del suelo constituye, en este estudio, una herramienta útil para tomar dimensión del proceso de agriculturización y sus impactos asociados.

En función de lo expuesto los objetivos del presente estudio son: analizar los cambios en el uso del suelo en el partido de Tandil, inserto en la RPA, para los años 1988 y 2015 a partir de imágenes clasificadas; calcular las tasas de cambio de uso anual para cada tipo de cobertura identificada; explorar las tendencias del proceso de agriculturización sobre diferentes paisajes del Partido; determinar los cultivos que poseen mayor incidencia en el proceso de agriculturización; e identificar los principales SE afectados por los cambios en el uso del suelo.

\section{Área de estudio}

La RPArg puede ser dividida en subregiones considerando la calidad de sus suelos y las precipitaciones. Los autores diferencian cinco áreas homogéneas: pampa ondulada, pampa central (con una porción más húmeda hacia el este y otra semiárida hacia el oeste), pampa austral, pampa deprimida o inundable y pampa mesopotámica. El partido de Tandil se halla ubicado en la denominada Pampa Austral (RPA) caracterizada por ser una pradera llana con suave declive al mar, por poseer suelos fértiles y un cordón serrano, el sistema de Tandilla y Ventania, que alberga una amplia diversidad de especies y ofrece un paisaje de valor ambiental y turístico. El Partido se localiza en el sector sudeste de la provincia de Buenos Aires (Figura 1), donde ocupa una superficie de 493500 ha. 


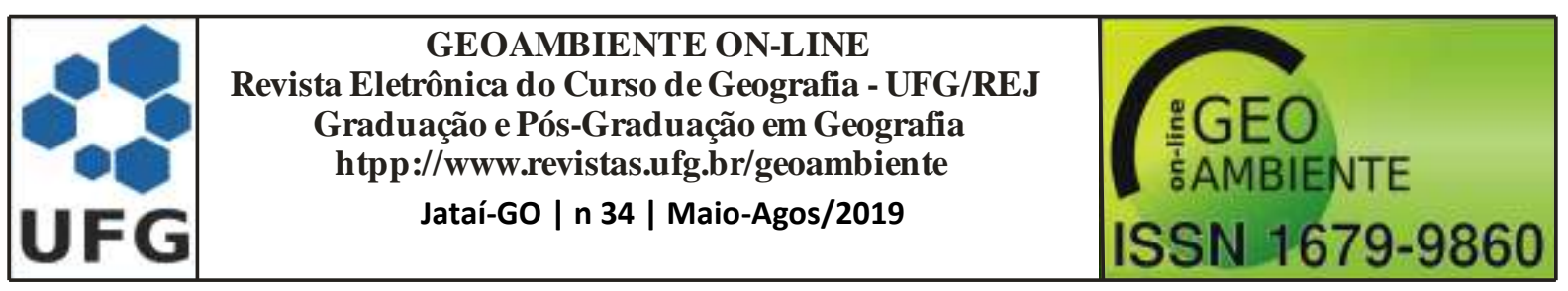

Figura 1. Localización del partido de Tandil, provincia de Buenos Aires, Argentina.

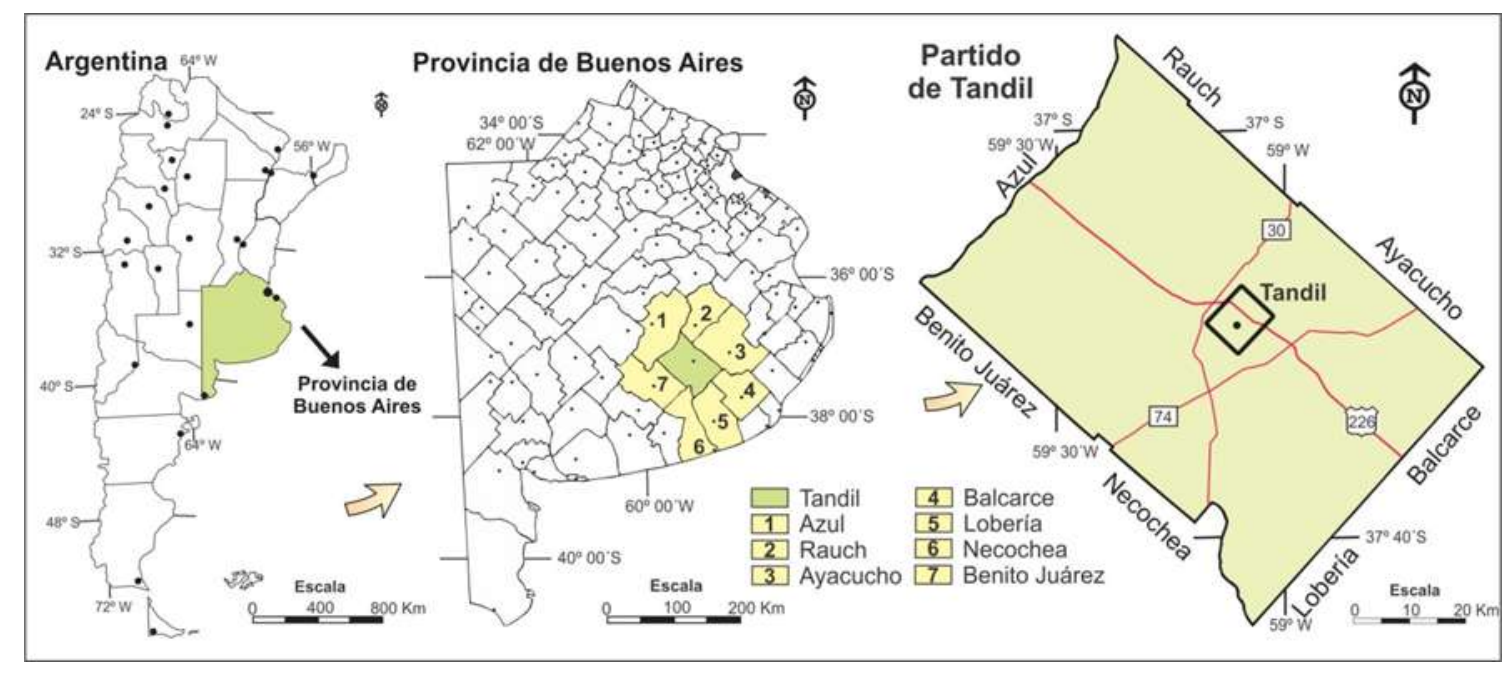

Fuente: VAZQUEZ Y ZULAICA, 2012.

SÁNCHEZ et al. (1999) diferenciaron y caracterizaron tres grandes compartimentos ecológicos presentes en el Partido: Serranías, Llanura periserrana y Planicie distal o deprimida. A continuación, y según lo analizado por SÁNCHEZ et al. (1999), en la Tabla 1, pueden observarse las características ecológicas de los sistemas:

Tabla 1. Compartimentos ecológicos de los tres principales sistemas del partido de Tandil.

\begin{tabular}{|c|c|}
\hline & Atributos ecológicos del sistema de Serranías \\
\hline Atributos & Características \\
\hline $\begin{array}{l}\text { Alturas, } \\
\text { pendientes y } \\
\text { características } \\
\text { geomorfológicas }\end{array}$ & $\begin{array}{l}\text { Altitudes superiores a los } 200 \mathrm{~m} \text {, con máximos del orden de los } 500 \\
\text { m. } \\
\text { Pendientes que generalmente superan el } 10 \% \text {. } \\
\text { Relieve serrano con predominio de cumbres y laderas empinadas. }\end{array}$ \\
\hline $\begin{array}{l}\text { Rocosidad y } \\
\text { pedregosidad }\end{array}$ & $\begin{array}{l}\text { Presencia importante de afloramientos rocosos más o menos } \\
\text { continuos en cúspides y laderas. } \\
\text { Presencia ocasional de afloramientos y ocurrencia frecuente de } \\
\text { bloques rocosos y/o pedregosidad en faldeos y techos de lomadas. }\end{array}$ \\
\hline $\begin{array}{c}\text { Condiciones } \\
\text { edáficas }\end{array}$ & $\begin{array}{l}\text { Presencia de proporciones considerables de suelos de entre } 5 \text { y } 30 \mathrm{~cm} \\
\text { de espesor con contactos líticos próximos a la superficie. } \\
\text { Desarrollo frecuente de hapludoles líticos. }\end{array}$ \\
\hline $\begin{array}{l}\text { Escurrimiento } \\
\text { superficial e } \\
\text { infiltración }\end{array}$ & $\begin{array}{l}\text { Presencia de abundantes cabeceras de vertientes de los arroyos de } \\
\text { Tandil. } \\
\text { Impedimentos en la infiltración de excesos de agua, parcialmente } \\
\text { compensados por el potencial de escurrimiento subsuperficial } \\
\text { facilitado por la declividad de las rocas subyacentes. }\end{array}$ \\
\hline
\end{tabular}




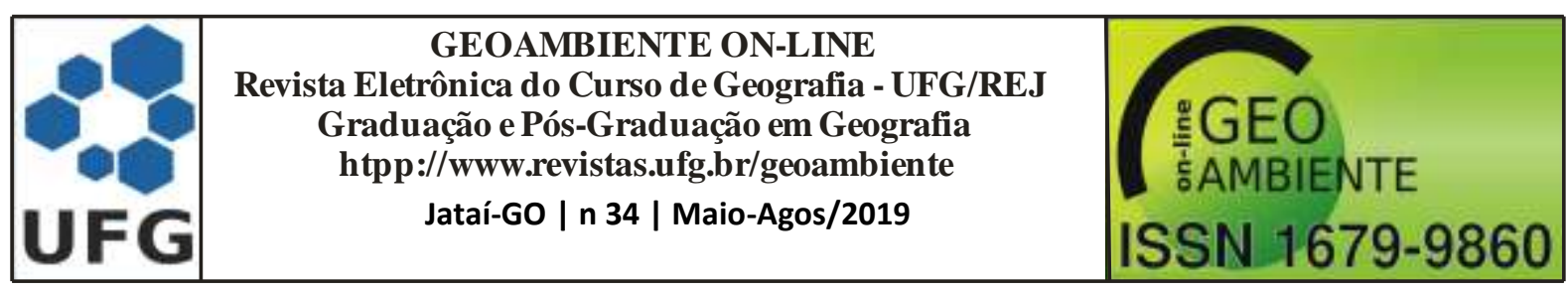

Presencia de las especies Eupatorium tweedianum y Hysterionica pinifolia en ambientes rocosos.

Presencia de pastizales en los que abundan gramíneas pertenecientes a los géneros Stipa y Piptochaetium (comunidad de flechillar) o

Vegetación gramíneas de la especie Paspalum quadrifarium (comunidad de paja colorada) o especies de plantas herbáceas pertenecientes al género Eryngium.

En sectores más húmedos, la Cortaderia selloana es la gramínea dominante.

En los ambientes rocosos húmedos, se destaca Baccharis tandilensis.

\begin{tabular}{|c|c|}
\hline & Atributos ecológicos de la Llanura periserrana \\
\hline Atributos & Características \\
\hline $\begin{array}{l}\text { Alturas, } \\
\text { pendientes y } \\
\text { características } \\
\text { geomorfológicas }\end{array}$ & $\begin{array}{l}\text { Altitudes comprendidas entre los } 200 \text { y } 300 \mathrm{~m} \text { en sus contactos con } \\
\text { las Serranías y alturas del orden de } \operatorname{los} 130-170 \mathrm{~m} \text { en el contacto con } \\
\text { las áreas de relieve plano. } \\
\text { Dominancia de pendientes comprendidas entre el } 2 \% \text { y cerca del } \\
10 \% \text {, en amplias áreas de relieve ondulado. } \\
\text { Dominancia de pendientes largas y declividades variables entre } 0.5 \text { y } \\
2 \% \text { en relieves ligeramente ondulados. }\end{array}$ \\
\hline $\begin{array}{l}\text { Rocosidad y } \\
\text { pedregosidad }\end{array}$ & $\begin{array}{l}\text { Presencia ocasional de pequeños sectores con afloramientos rocosos } \\
\text { y/o pedregosidad en superficie, principalmente en las lomadas y } \\
\text { pendientes vecinas al pedemonte. }\end{array}$ \\
\hline $\begin{array}{l}\text { Condiciones } \\
\text { edáficas }\end{array}$ & $\begin{array}{l}\text { Variabilidad de suelos, principalmente en sectores en donde existe } \\
\text { una variación rápida de geoformas cóncavas y convexas. } \\
\text { Presencia frecuente de tosca a profundidades diferentes, sobre todo en } \\
\text { las geoformas pronunciadamente convexas (a aproximadamente } 1 \mathrm{~m} \\
\text { en suelos relativamente profundos y a menos de } 0,5 \mathrm{~m} \text { en suelos } \\
\text { someros). } \\
\text { Dominancia de suelos pertenecientes al Gran Grupo Argiudol } \\
\text { (argiudoles típicos, principalmente). } \\
\text { Presencia poco representativa de suelos con régimen ácuico de } \\
\text { humedad en los sectores deprimidos. }\end{array}$ \\
\hline $\begin{array}{l}\text { Escurrimiento } \\
\text { superficial e } \\
\text { infiltración }\end{array}$ & Moderado potencial de escurrimiento superficial e interno. \\
\hline Vegetación & $\begin{array}{l}\text { En la vegetación primitiva de los pastizales de la pampa del sudoeste } \\
\text { bonaerense dominan gramíneas de los géneros Stipa y Piptochaetium, } \\
\text { difundiendo los mismos grupos de hierbas de hojas anchas de la } \\
\text { pampa ondulada. } \\
\text { La vegetación nativa es prácticamente inexistente porque ha sido } \\
\text { sustituida por cultivos, tanto de renta como forrajeros. }\end{array}$ \\
\hline & Atributos ecológicos de la Llanura distal \\
\hline Atributos & Características \\
\hline $\begin{array}{l}\text { Alturas, } \\
\text { pendientes y }\end{array}$ & del orden de 112-115 m. y máximas comprendidas \\
\hline
\end{tabular}




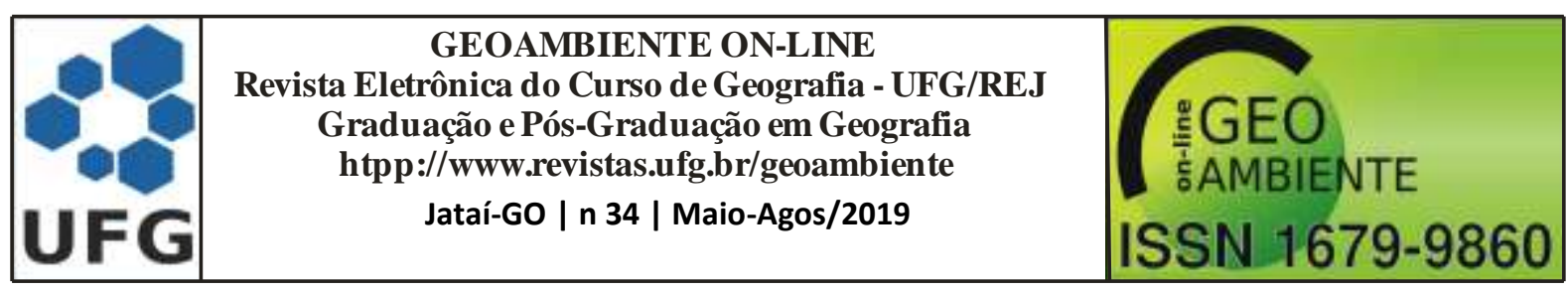

características
geomorfológicas

Presencia de considerables proporciones de paisajes aplanados, de escasa declividad general (inferior al $0.2 \%$ ).

Presencia de pendientes de formas inconstantes debido a la existencia de irregularidades muy sutiles del relieve, entre las que se destacan numerosas cubetas de atributos y dimensiones diversas.

Presencia de paisajes con pendientes de poca declividad $\mathrm{y}$ relativamente constantes $(0.2-0.3 \%)$.

Presencia de algunos paisajes de relieve plano y relativamente extendido, pero que asocian ocasionales segmentos convexos de pequeña dimensión espacial (lomas).

Presencia de suelos pertenecientes al Gran Grupo Argiudol (argiudoles típicos) en las planicies bien drenadas.

Condiciones edáficas

Presencia de natracuoles típicos y ocasionalmente hapludoles taptonátricos en las planicies más deprimidas y eventualmente en algunas lomas.

Bajo potencial de escurrimiento superficial e interno.

Escurrimiento
superficial e
infiltración

Vegetación

Presencia de sectores con cubetas que poseen fuertes restricciones para eliminar los excesos de agua superficial.

Presencia de sectores con moderadas a buenas condiciones de drenaje interno y superficial (paisajes de planicies con pendientes relativamente constantes).

Fuera de las áreas mejor drenadas (argiudoles típicos), si fueran extrapolables los reconocimientos de grupos florísticos caracterizados en otras áreas de la pampa deprimida bonaerense, mostraría tres variantes: una de ellas con dominancia de Mentha pulegium y Leontodon taraxacoides, y las otras dos con dominancia de Alternantera philoxeroides y Ludwigia peploides.

Presencia de pajonales con dominancia de la especie Paspalum quadrifarium (comunidad de paja colorada).

Presencia de comunidades de plantas representadas fundamentalmente por las especies Distichlis spicata y Distichlis scoparia.

Fuente: Elaboración propia en base a SÁNCHEZ et al. (1999).

\section{Material y métodos}

Con la finalidad de analizar los cambios en el uso del suelo en el partido de Tandil durante el período 1988-2015 se obtuvieron dos imágenes satelitales captadas por el sensor TM de la misión Landsat 5 y por el sensor OLI de la misión Landsat 8, correspondientes a las fechas: 06-09-1988 y 04-06-2015, con Path and Row 225/86. La imagen Landsat 5 fue obtenida del Instituto Nacional de Pesquisas Espaciais (INPE, 2017), mientras que la imagen Landsat 8 fue obtenida de la página del U. S. Geological Survey (USGS, 2018). 


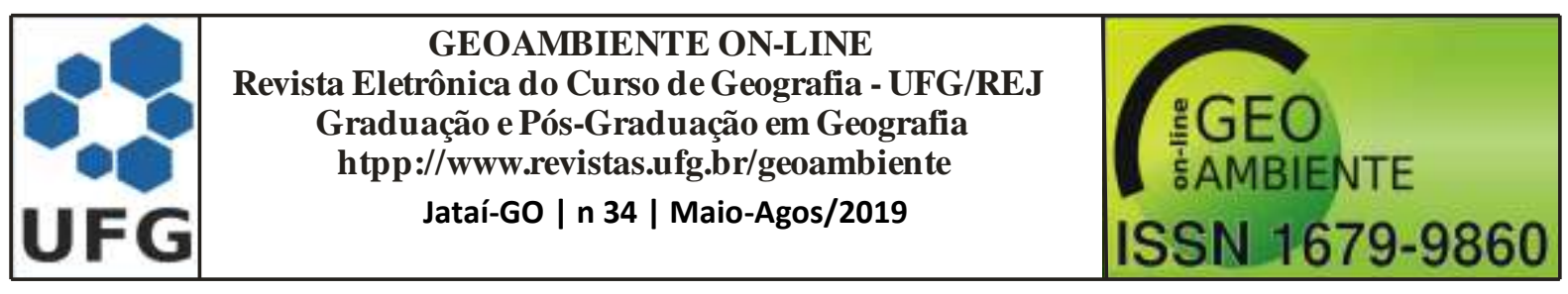

Las imágenes se procesaron mediante el Software ENVI 5.1 (RESERCH SYSTEM INC., Boulder, CO, USA). Se efectuaron correcciones atmosféricas debido a que la radiación electromagnética, captada por los sensores de los satélites, atraviesa la atmósfera y es modificada por efecto de la dispersión como consecuencia de la interacción con las moléculas y partículas de la atmósfera (LILLESAND et al., 2014). El proceso de corrección atmosférica logra mejorar la calidad visual de la imagen así como eliminar el componente intrusivo de la atmósfera (AGUILAR ARIAS et al., 2014).

Los valores de los píxeles en las imágenes satelitales expresan la cantidad de energía radiante recibida por el sensor en la forma de valores relativos no calibrados llamados Números Digitales (ND) o brillo. En ocasiones, cuando se realiza la clasificación no supervisada de una imagen con fecha única, no es necesario convertir estos valores (EASTMAN, 2004). En cambio, si se trata de realizar comparaciones entre imágenes de distintas fechas y de las mismas áreas (tal como sucede en este caso de estudio) es necesario realizar las correcciones de los datos de manera que sean comparables tal como lo proponen CHANDER et al. (2007).

Luego, se georreferenciaron las imágenes empleando como imagen base la proporcionada por el recorte de un mosaico de imágenes (www.landcover.org). En este caso se realizó considerando 20 puntos que tomaban el mismo sector en cada imagen y, a través de una interpolación matricial realizada por el software. En principio se llevaron todas las imágenes a la proyección UTM- Datum WGS-84 - Zona 21 Sur. Para la obtención de estos puntos de control, se realizó una campaña de trabajo de campo a través de la cual se adquirieron datos de terreno y puntos de GPS (Global Positioning System).

Posteriormente, se procedió a la realización de una clasificación supervisada (CS) tomando como punto de partida las imágenes procesadas de 1988 y 2015 donde se definieron cinco grandes clases de uso. En la fase de asignación se aplicó el Clasificador de Máxima Probabilidad.

Considerando cada clase de uso propuesta por en este trabajo se obtuvieron los estadísticos de la CS para cada año en el Partido, verificándose en campo los resultados obtenidos para cada punto de control. A su vez, se calcularon las tasas de cambio anual para cada año seleccionado y para cada clase definida. Para ello se utilizó la fórmula [1] que propone la FAO (2005), para cualquier tipo de cobertura: 


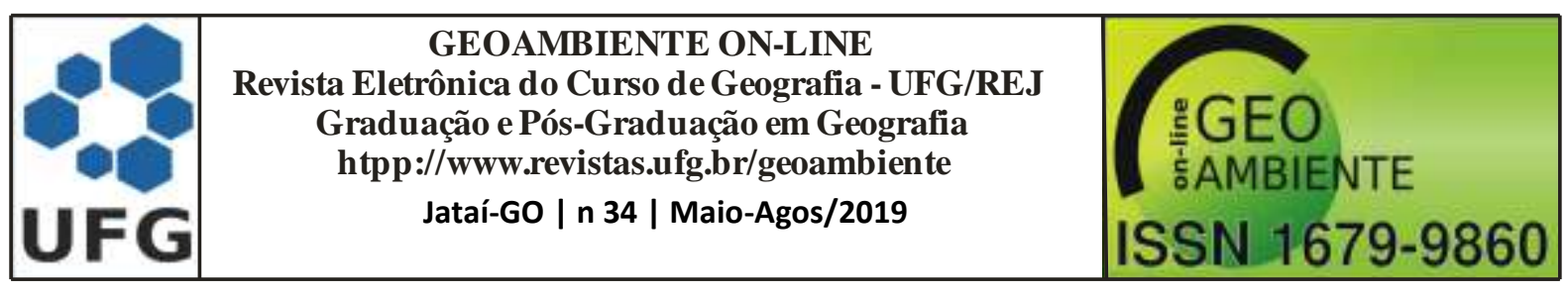

$$
\text { [1] } \delta=\left(\frac{S_{2}}{S_{1}}\right)^{1 / n}-1
$$

Dónde:

$\delta$ : expresa la tasa de cambio anual de cada clase de uso de suelo en el período 2003-2011;

S1: superficie en la fecha 1;

S2: superficie en la fecha 2;

n: número de años entre las dos fechas.

Para caracterizar de manera preliminar las diferenciaciones en los cambios de uso de suelo generados por el avance de la agricultura al interior del Partido fueron vectorizados los compartimentos principales determinados por SÁNCHEZ Y ZULAICA (2002). Basados en la definición del concepto de paisaje (BUREL Y BAUDRY, 2002) su aplicación permite delimitar, identificar y caracterizar unidades que presentan cierta homogeneidad interna en la escala de análisis adoptada (1:500000). Los paisajes del partido de Tandil se delimitaron integraron los atributos bióticos y abióticos: geomorfológicos, edáficos, condiciones de drenaje y vegetación. Cada uno de estos atributos se representó espacialmente en distintas capas de información utilizando gvSIG (versión 1.11) y se integraron mediante el módulo de geoprocesamiento de este software.

Para determinar los cultivos con mayor incidencia en el proceso de agriculturización se recurrió a estadísticas oficiales del Portal de Datos Abiertos del Ministerio de Agroindustria (2018), entrevistas a cerealeras e informantes calificados. Finalmente, la identificación esquemática de los principales SE afectados por los cambios involucrados en el mencionado proceso se obtuvo a partir de estudios antecedentes y relevamientos de campo.

\section{Resultados y Discusiones}

Cambios en el uso del suelo y tendencias del proceso de agriculturización sobre diferentes paisajes del partido de Tandil (1988-2015)

La CS de las imágenes satelitales (Figura 2) permite apreciar los tipos de cobertura presentes en el Partido para el año 1988 y 2015. Se observan las transformaciones acontecidas a lo largo de veintisiete años en los usos del suelo de los tres compartimentos ecológicos característicos. 


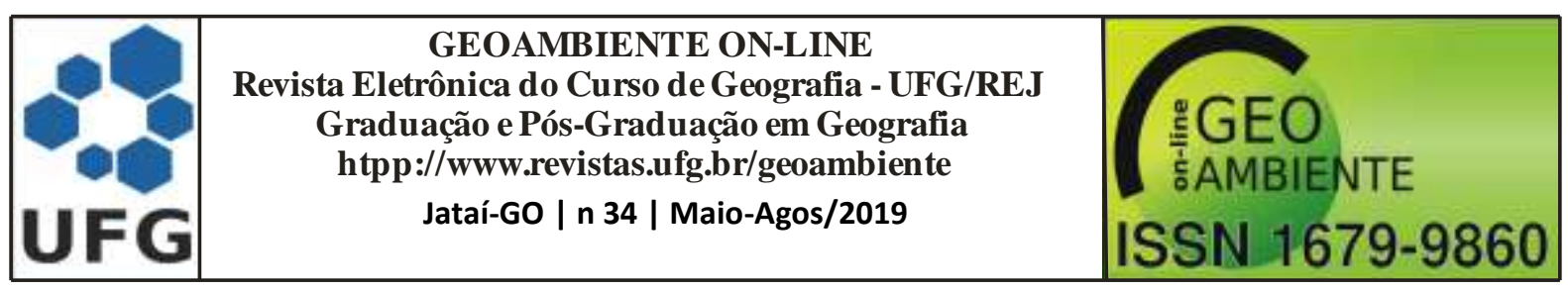

Se han identificado como clases de uso del suelo: áreas con pastizales y pasturas, áreas con cuerpos de agua, áreas urbanas y áreas agrícolas diferenciadas entre áreas cultivables (sin cultivos en el momento en que fue tomada la imagen) y cultivadas. Las áreas cultivables y cultivadas representan en conjunto el total de agrícolas, mientras que las ocupadas con pastizales y pasturas, las ganaderas. La Tabla 2 presenta la superficie correspondiente a cada clase.

Se observa (Figura 2 - Tablas 2 y 3) que en el año 1988 dominaban en el partido de Tandil las áreas con pastizales y pasturas naturales ocupando, aproximadamente, el 60\% del área de estudio $\left(2934.40 \mathrm{~km}^{2}\right)$. El mayor porcentaje de dichas áreas estaba distribuido en los compartimentos ecológicos de la Llanura distal y Serranías. Por su parte, el compartimento de la Llanura periserrana contenía parches de áreas de pastizales y pasturas junto con parches de áreas cultivables y cultivadas. En su conjunto, las áreas agrícolas representaban el 38\% de la superficie del Partido $\left(1880 \mathrm{~km}^{2}\right)$ y su presencia se destacaba en los límites entre compartimentos. Se observa su marcada distribución en el límite de los compartimentos de Llanura distal y Llanura periserrana y en los límites de las Serranías con la zona de Llanura periserrana.

El análisis espacial de los resultados obtenidos para 2015 permite identificar como cambio trascendental la limitación o exclusión de las zonas ganaderas, es decir las áreas cubiertas con pastizales y pasturas, a un sector de la Llanura distal en el Noroeste del Partido. A su vez, se identificó su presencia en pequeños parches en la Llanura periserrana. Para este período, la ganadería ocupaba el $25.67 \%$ de la superficie del Partido $\left(1266 \mathrm{~km}^{2}\right)$. En síntesis, la superficie destinada a dicha actividad productiva disminuye, en veintisiete años, un $56.85 \%$ a una tasa anual del $2.1 \%$.

En contraste, las zonas agrícolas se expanden en los tres compartimentos un $71.83 \%$, a una tasa de crecimiento anual de $3.28 \%$. Por lo tanto, las áreas cultivables y cultivadas representan, en el segundo año analizado, el $72 \%$ de la superficie total de Tandil $\left(3545 \mathrm{~km}^{2}\right)$. 


\begin{tabular}{|c|c|c|}
\hline & $\begin{array}{c}\text { GEOAMBIENTE ON-LINE } \\
\text { Revista Eletrônica do Curso de Geografia - UFG/REJ } \\
\text { Graduação e Pós-Graduação em Geografia } \\
\text { htpp://www.revistas.ufg.br/geoambiente } \\
\text { Jataí-Go | n } 34 \text { | Maio-Agos/2019 }\end{array}$ & $\begin{array}{c}\text { GEO } \\
\text { GF }\end{array}$ \\
\hline
\end{tabular}

Figura 2. Compartimentos ecológicos y cambios en los usos del suelo de Tandil 1988-2015.
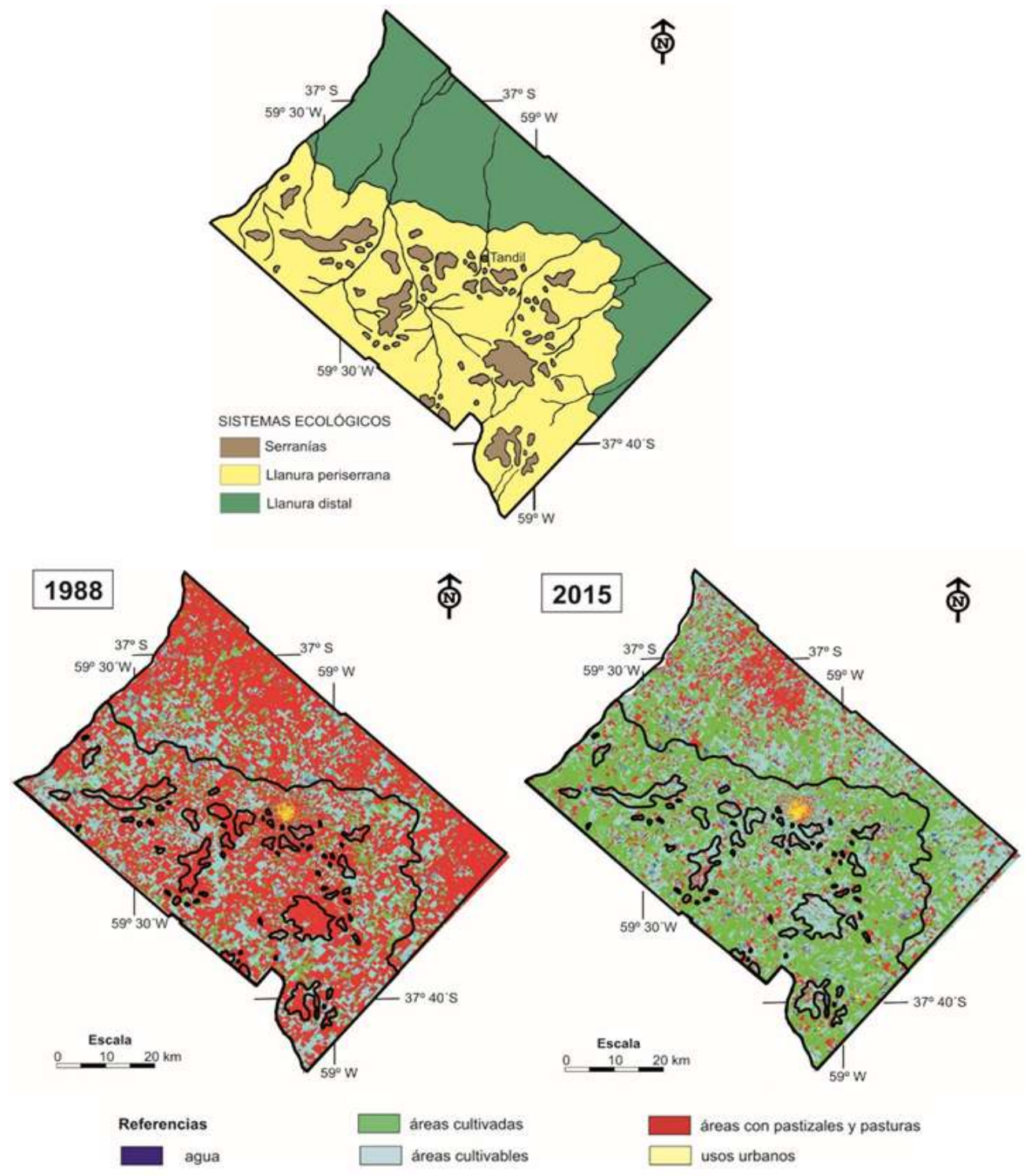

Fuente: Elaboración propia.

Tabla 2. Cambios en los usos del suelo del partido de Tandil 1988-2015.

\begin{tabular}{|c|c|c|c|c|}
\hline Clases & Superficie $1988\left(\mathrm{~km}^{2}\right)$ & $\%$ & Superficie $2015\left(\mathrm{~km}^{2}\right)$ & $\%$ \\
\hline Usos urbanos & 22.4 & 0.45 & 43.60 & 0.88 \\
\hline $\begin{array}{l}\text { Áreas con pastizales y } \\
\text { pasturas }\end{array}$ & 2934.40 & 59.46 & 1266 & 25.65 \\
\hline $\begin{array}{c}\text { Áreas cultivadas } \\
\text { Áreas a cultivar }\end{array}$ & $\begin{array}{c}455.2 \\
1424.50\end{array}$ & 38.09 & $\begin{array}{l}1977.20 \\
1567.80 \\
\end{array}$ & 71.83 \\
\hline Agua & 98.7 & 2.00 & 80.40 & 1.63 \\
\hline Superficie del Partido & 4935 & 100 & 4935 & 100 \\
\hline
\end{tabular}

Fuente: Elaboración propia. 


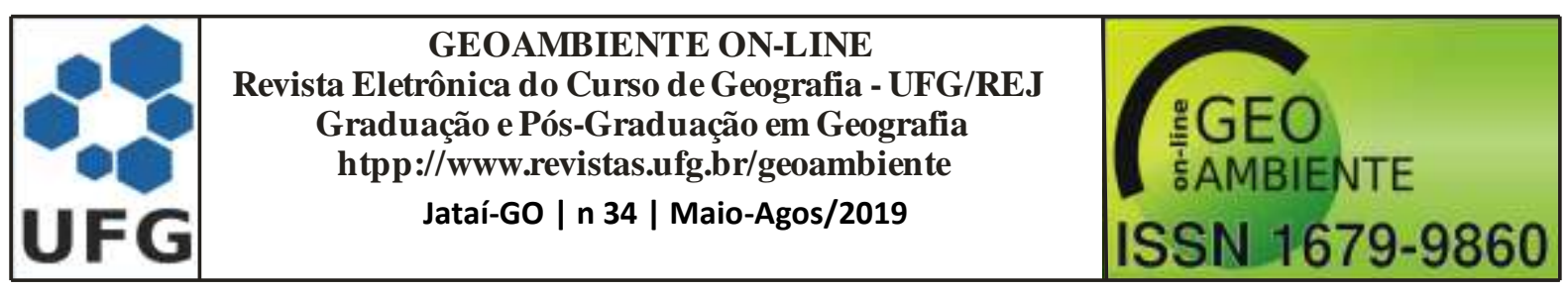

Tabla 3. Tasas de cambios en los usos del suelo del partido de Tandil 1988-2015.

\begin{tabular}{ccc}
\hline Tipo de cobertura & Tasa & Tasa anual \\
\hline Usos urbanos & 94.641 & 3.505 \\
\hline Áreas con pastizales y pasturas & -56.856 & -2.105 \\
\hline Áreas agrícolas & 88.593 & 3.281 \\
\hline Agua & -18.541 & -0.686 \\
\hline
\end{tabular}

Fuente: Elaboración propia en base a datos del Ministerio de Agroindustria (2018).

Se han identificado tendencias sustanciales del proceso de agriculturización sobre diferentes paisajes del Partido. Las condiciones climáticas favorables y la presencia de suelos con buena aptitud agrícola, especialmente en la Llanura distal, hacen que el área se encuentre extensivamente ocupada por agroecosistemas. Dicho contexto ha generado una exponencial incorporación de plaguicidas, particularmente herbicidas, aumento del uso de fertilizantes, expansión del doble cultivo (cereal/oleaginosa), disminución de la superficie ganadera, fuerte fragmentación de hábitats e importante disminución de la eficiencia energética de los agroecosistemas. Ante esta situación en el Partido comienzan a observarse nuevas conductas respecto a los productores, tales como la incorporación de la certificación a partir de Buenas Prácticas Agrícolas (SOMOZA et al., 2018) y prácticas agroecológicas (VAZQUEZ Y VIGNOLLES, 2015).

Vale remarcar el avance de la agricultura hacia zonas con mayores riesgos ecológicos y por ende productivos. En primera instancia la expansión de la actividad agrícola ocurrió en el compartimento de la Llanura periserrana caracterizada por poseer los suelos más fértiles del Partido (Argiudoles típicos). En segunda instancia, por un lado, el crecimiento superficial de la actividad alcanza zonas bajas, con suelos menos productivos y con mayor riesgo de anegamiento correspondientes al compartimento de la Llanura distal. Por otro lado, alcanza zonas serranas donde pueden desarrollarse inconvenientes asociados a la erosión hídrica.

Cabe mencionar ciertas características de la actividad ganadera en el período analizado fomentadas por la competencia con la agricultura que indujo cambios de localización e intensidad de los usos ganaderos cárnicos y lácteos. El proceso de agriculturización favoreció la reducción de la superficie ganadera y la confinó a áreas menos productivas como, por ejemplo, sectores de la Llanura distal con bajo potencial de escurrimiento superficial e interno. No obstante, a pesar de dicha disminución asociada a una fuerte caída en el número 


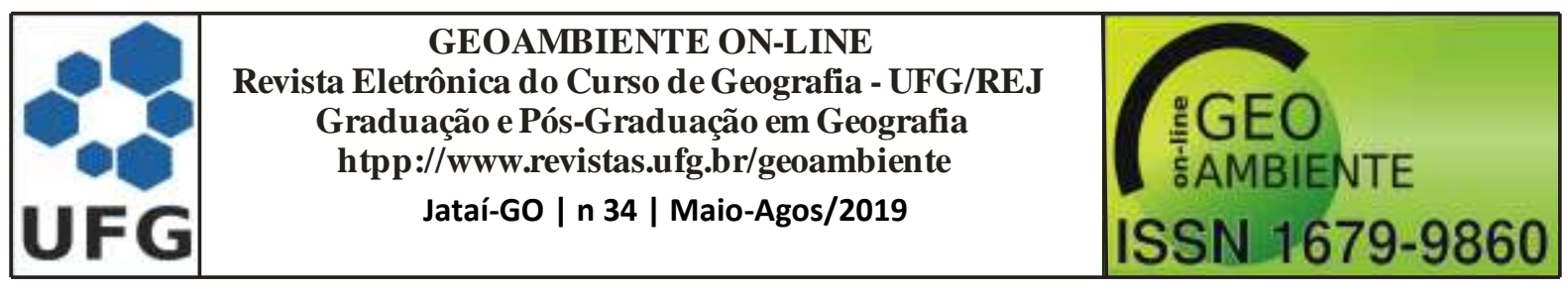

de explotaciones con ganado bovino se observa la presencia de un stock relativamente estable, una intensificación productiva y una mayor eficiencia de la misma. En 1988 el stock total de bovinos era de 345105 cabezas de ganado bovino, mientras que en 2015 se identificaron 303166 cabezas en el Partido (MINISTERIO DE AGROINDUSTRIA, 2018). A su vez, esta situación fue potenciada por el rol de la actividad ganadera como reserva de capital (sobre todo en períodos de crisis institucional, política y macroeconómica), por un mayor número de animales por superficie, menor tiempo de engorde, alimentación en base a granos y concentrados, mayor dotación de insumos, estímulos económicos como subsidios (decreto $\mathrm{N}^{\circ}$ 4211/2010 de la ONCCA a través del cual se subvencionó la instalación de feed lots para favorecer el abastecimiento del mercado interno) (NOGAR et al, 2017).

La superficie ocupada por áreas urbanas aumentó en el período analizado un 94\%. En el año 1988 su superficie era de $22.4 \mathrm{~km}^{2}$ mientras que para 2015 era de $43.6 \mathrm{~km}^{2}$. Dichos resultados coinciden con el importante crecimiento demográfico e inmobiliario del partido de Tandil evidenciado en los datos censales. La población del partido en 1991 era de 101228 habitantes (INDEC, 1991) y en el año 2010 (último dato oficial disponible) era de 123871 habitantes lo cual representa un aumento poblacional del 22\% (INDEC, 2010). Coincidiendo con lo representado en la Figura 2 para el año 2015, FERNÁNDEZ Y RAMOS (2017) observan (en las últimas dos décadas) un modelo disperso de crecimiento urbano, cercano al área central, pero que no encuentra ningún tipo de barreras en los faldeos serranos.

Con respecto al área ocupada por cuerpos de agua superficial se observa una disminución del 18.54\%. En 1988 dicha cobertura estaba presente en $98.7 \mathrm{~km}^{2}$ y en 2015 ocupaba $80.4 \mathrm{~km}^{2}$. No obstante, el año 1988 se asocia a un año seco caracterizado por el fenómeno de la Niña en el cual se registraron $798.4 \mathrm{~mm}$ de precipitaciones anuales; el año 2015 se caracterizó por ser más húmedo debido al fenómeno del Niño y se registraron 998 mm de precipitaciones anuales (CLIMATE PREDICTION CENTER, 2018). El descripto proceso de agriculturización, que se tradujo en la reducción de áreas destinadas a pastizales naturales y pasturas, se vio favorecido por la presencia de un período más seco que tuvo sus comienzos a mediados de la década del año 2000 (2005: $627.8 \mathrm{~mm}$; 2006: $784.7 \mathrm{~mm}$; 2007: $621.4 \mathrm{~mm}$; 2008: $551.3 \mathrm{~mm}$; 2009: $628.8 \mathrm{~mm})$. 


\begin{tabular}{|c|c|c|}
\hline & $\begin{array}{c}\text { GEOAMBIENTE ON-LINE } \\
\text { Revista Eletrônica do Curso de Geografia - UFG/REJ } \\
\text { Graduação e Pós-Graduação em Geografia } \\
\text { htpp://www.revistas.ufg.br/geoambiente } \\
\text { Jataí-Go | n } 34 \text { | Maio-Agos/2019 }\end{array}$ & $\begin{array}{c}\text { GEO } \\
\text { GF }\end{array}$ \\
\hline
\end{tabular}

Variación de la superficie sembrada con principales cultivos

El proceso de agriculturización contempla el avance de la actividad agrícola con el consecuente retroceso de la ganadería y la intensificación tecnológica. No obstante, analizado la variación de la superficie destinada a los principales cultivos durante el período seleccionado se ha detectado otra característica propia de dicho proceso: una brusca variación en las hectáreas destinadas a los principales cultivos agrícolas que se observan en la Tabla 4 y la Figura 3.

Tabla 4. Tasas de variación en la superficie de principales cultivos.

\begin{tabular}{cccccccc} 
& Avena & Cebada & Colza & Trigo & Girasol & Maíz & Soja \\
\hline $\begin{array}{c}\text { Tasas de variación } \\
(\mathbf{1 9 8 8}-\mathbf{2 0 1 5})\end{array}$ & -0.031 & 0.233 & -0.031 & -0.049 & -0.004 & 0.015 & 0.115 \\
\hline
\end{tabular}

Fuente: Elaboración propia en base a datos del Ministerio de Agroindustria (2018).

Figura 3. Evolución de la superficie destinada a principales cultivos.

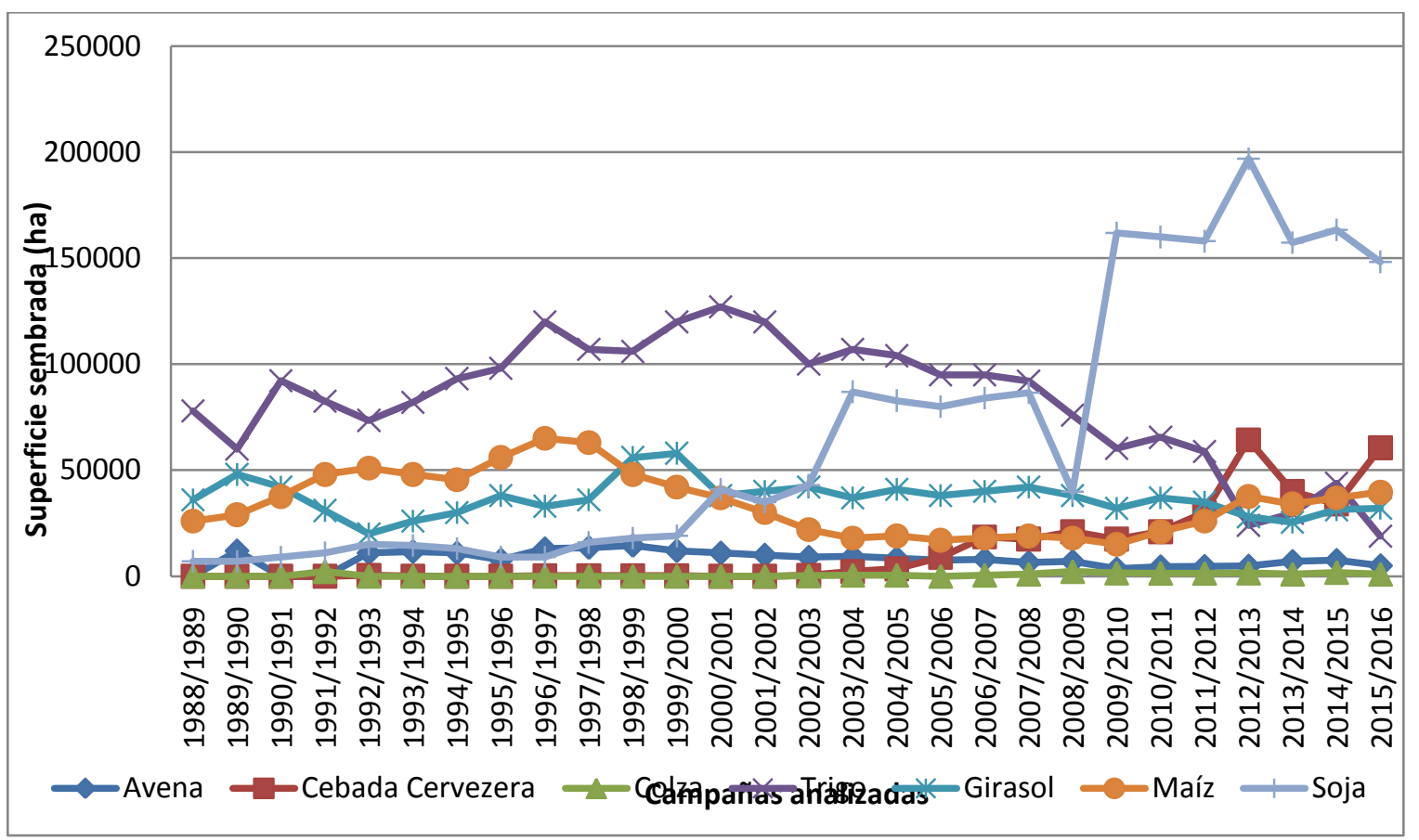

Fuente: Elaboración propia en base a datos del Ministerio de Agroindustria (2016).

Al comparar los datos de la superficie destinada a los principales cultivos en 1988 respecto de 2015 se observa una importante modificación en la dominancia de los cultivos 


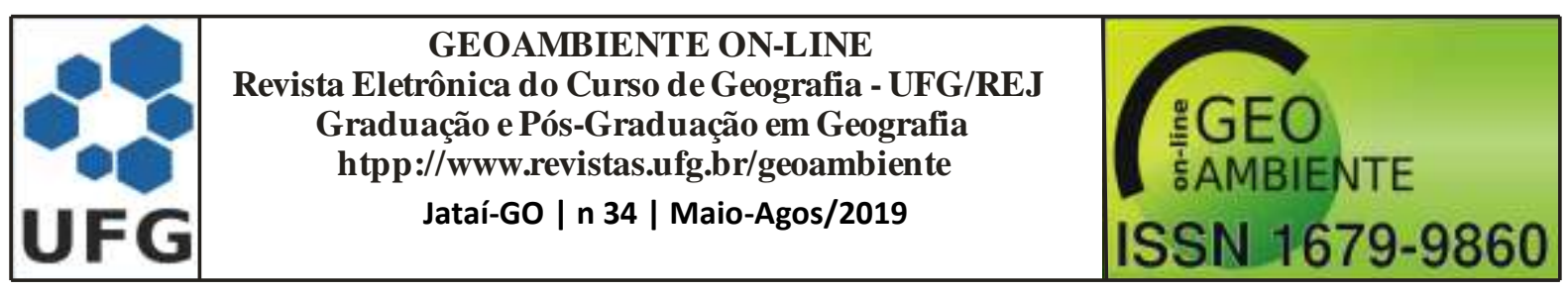

(Figura 4). Con respecto a los cultivos de cosecha gruesa el girasol es el único cultivo que presenta una disminución en su superficie. Los cultivos de soja y maíz evidencian una tasa de variación positiva de las hectáreas sembrada con un aumento de 2019\% y 52\%, respectivamente. La soja posee el incremento de superficie más estable campaña tras campaña a pesar del notorio declive de la campaña 2008-2009. El maíz mantiene su lugar de importancia en el agro del Partido si bien se observa una disminución en su superficie a lo largo del período. Las variaciones sufridas por este cultivo campaña tras campaña acompañan a los cambios evidenciados en todos los cultivos de modo general. Cabe destacar su papel en las campañas 1996-1997 y 1997-1998 en las cuales fue el segundo cultivo dominante, luego del trigo, con 65000 y 63000 ha respectivamente.

Figura 4. Comparación de las hectáreas destinadas a los principales cultivos en la primera y última campaña analizada ${ }^{*}$.

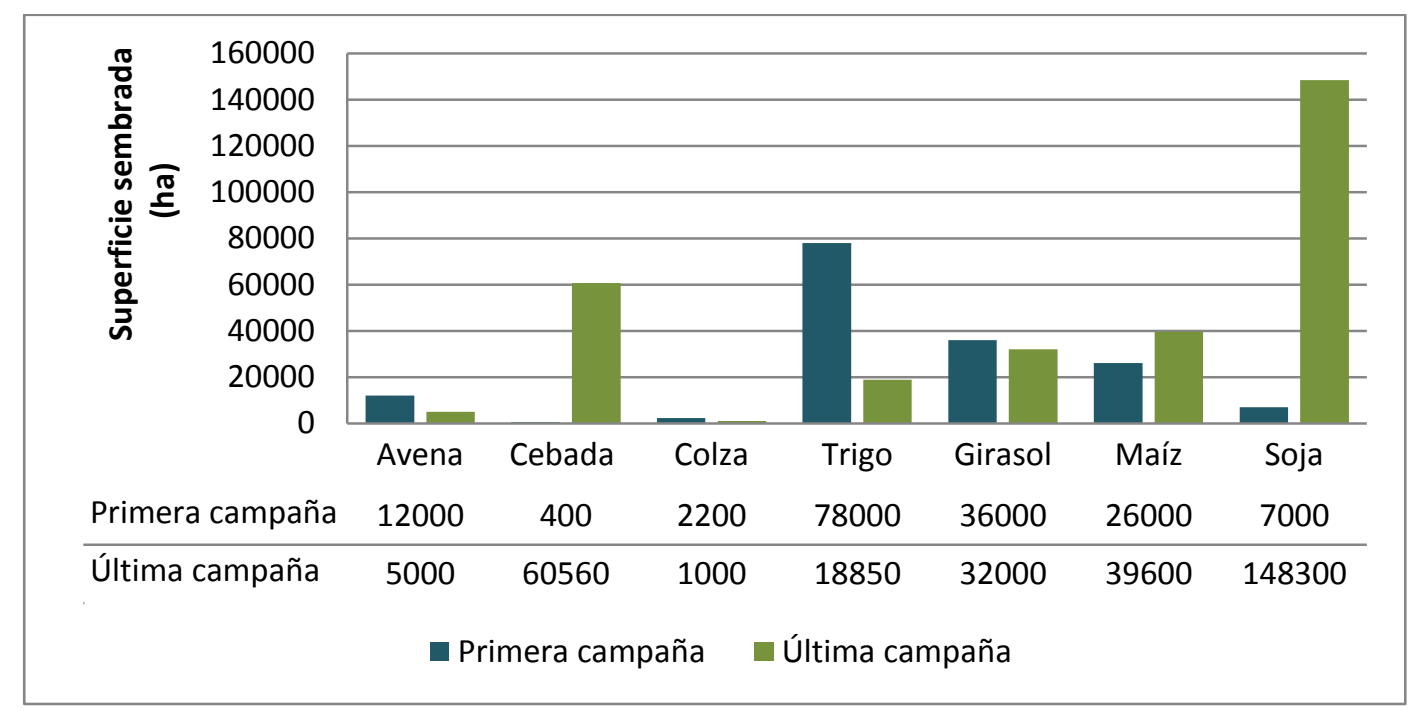

Fuente: Elaboración propia en base a datos del Ministerio de Agroindustria (2018).

* La primera campaña considerada varía según el cultivo. Se ha considerado como primera campaña aquella a partir de la cual se registra una siembra continua de cada cultivo: 1988-1989: Trigo, Girasol, Maíz, Soja; 1989-1990: Avena; 1992-1993: Cebada y 1991-1992: Colza. Última campaña: 20152016.

En cuanto a los cultivos de cosecha fina tanto la avena, colza y trigo presentan una tasa de cambio negativa en sus hectáreas. Las hectáreas de avena disminuyen un 58\%. La tasa de disminución de la colza iguala al cultivo de avena (-0.031). Sin embrago, debe 


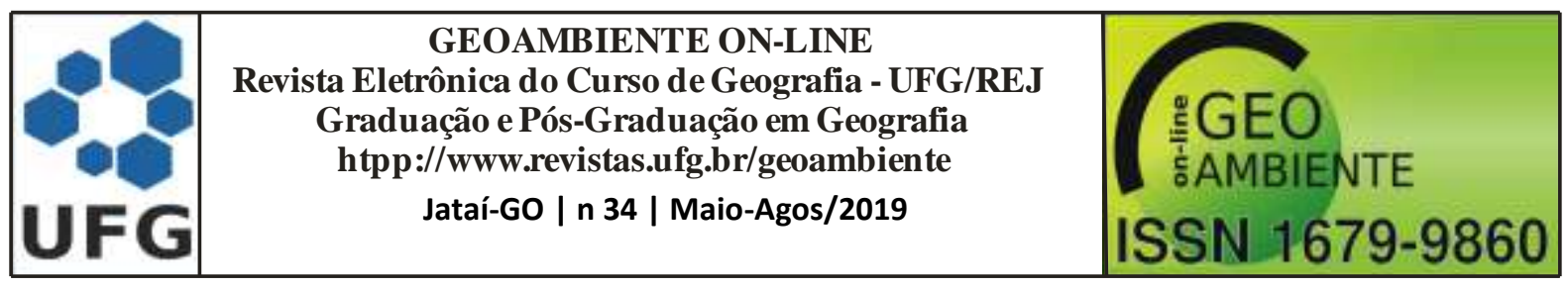

considerarse que no se registró superficie sembrada con colza a lo largo de diez campañas (1992-1993/2001-2002). Es a partir de la campaña 2002-2003 que vuelve a aparecer en el escenario del agro tandilense. Por su parte, el trigo evidencia la merma de superficie más significativa con una tasa de -0.049 y una pérdida de 76\%. La campaña 2009-2010 es en la cual deja de ser el cultivo dominante a nivel Partido pasando a ser el quinto cultivo en orden de importancia en la última campaña analizada. Dentro del grupo de cultivos de cosecha fina la cebada cervecera es el único cultivo con una tasa de variación positiva. Dicha tasa representa la evolución en hectáreas sembradas más significativa con un aumento del 15 040\%. Al igual que la colza, en la campaña 2002-2003 vuelve a tener lugar en la actividad agrícola del Partido y en la última campaña considerada es el segundo cultivo dominante luego de la soja.

\section{Servicios ecosistémicos afectados}

La relación entre los SE y la producción primaria es interdependiente: un mejor estado de los servicios implica un sistema productivo más estable y con mayor capacidad de resiliencia ante cambios inesperados. De forma esquemática y a partir de los cambios identificados en los usos del suelo del Partido, promovidos en un contexto de intensificación tecnológica y productiva, es posible inferir aquellos SE cuya provisión resulta afectada favorable y desfavorablemente. Partiendo de lo postulado por MARTÍN-LÓPEZ Y MONTES (2011) se identifica que la gestión del territorio se encuentra focalizada en unos pocos servicios, principalmente de abastecimiento, implicando generalmente la degradación de servicios de regulación y culturales.

No obstante, al distinguir entre la producción intensiva o extensiva de los servicios de abastecimiento se observan ciertas diferencias. Tanto a nivel global como local la provisión de servicios que resulta potenciada es aquella obtenida de manera intensiva y dependiente de insumos externos, particularmente en el caso de la agricultura.

La merma o deterioro en la provisión de ciertos servicios está vinculada, a su vez, con la pérdida de biodiversidad en los agroecosistemas producida por el fenómeno de agriculturización. BALVANERA Y COTLER (2009) afirman que la provisión de prácticamente todos los SE es regulada por la biodiversidad. La diversidad biológica modula la productividad primaria (asociada a servicios como provisión de alimentos o de madera), el 


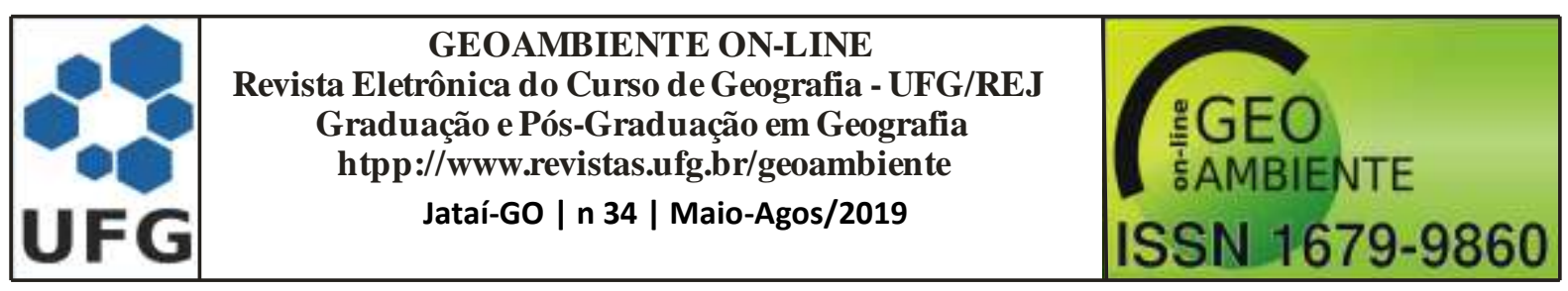

reciclaje de nutrientes y la formación y retención del suelo (asociados a servicios como el mantenimiento de la fertilidad y control de la erosión), o la regulación del ciclo hidrológico (asociada a servicios como la provisión de agua y regulación de su calidad). Por este motivo, la homogeneidad de los paisajes característica del contexto agrícola actual (tanto departamental como regional) genera impactos negativos sinérgicos. Al impactar negativamente sobre la base de los SE, la provisión de todos los servicios asociados se verá degradada tanto cualitativa como cuantitativamente.

Ante esta situación el análisis de la provisión de SE resulta útil para evaluar las consecuencias ambientales de las modificaciones descriptas. En el partido de Tandil donde se observa cómo el contexto de transformaciones agroproductivas resulta propicio para la provisión de servicios de abastecimiento. Dichos servicios poseen un reflejo en el mercado y por lo tanto son los considerados en la toma de decisiones (DE GROOT et al., 2010). Por consiguiente, resulta afectada directamente la sustentabilidad ecológica del partido de Tandil y por ende la capacidad productiva de los agroecosistemas. Lo anterior condice con lo expresado en el MEA (2005), donde se expone que la destrucción de hábitats naturales para producir alimentos u otros productos agrícolas destinados al consumo humano o animal (tal el caso de los afamados commodities) representan la más severa y extendida amenaza a la biodiversidad global. En este sentido surge la necesidad de implementar un sistema de seguimiento de los cambios en el nivel de provisión de SE que vuelva factible su incorporación a la planificación del territorio y la toma de decisiones (PARUELO, 2011).

\section{Consideraciones Finales}

- El uso de imágenes clasificadas y los datos proporcionados por entidades gubernamentales permitieron dar cuenta de los cambios en el uso del suelo y de las tendencias de diversas problemáticas ambientales asociadas al partido de Tandil en un período de veintisiete años. La transformación más evidente es el avance de la actividad agrícola sobre áreas ocupadas anteriormente por la actividad ganadera dando lugar a un notorio proceso intensificación productiva. En el área de estudio, el proceso de agriculturización no sólo se caracteriza por la expansión e intensificación de la agricultura sino también por una alteración en la dominancia de los cultivos relacionada a la superficie ocupada por cada uno. Se reconoce al cultivo de soja como 


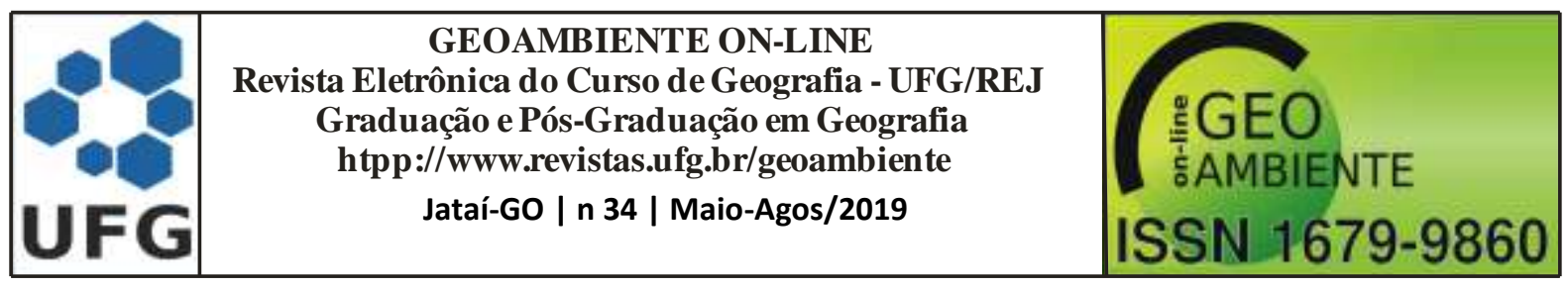

el principal traccionador del proceso. El análisis de los cambios de uso del suelo constituye una herramienta útil para tomar dimensión de las externalidades asociadas a la agriculturización.

- La gestión del territorio (o su ausencia) se encuentra focalizada en la provisión de aquellos servicios de abastecimiento obtenidos intensivamente en detrimento de la provisión de servicios de regulación. Urge el desarrollo e implementación de planes de gestión ambiental del territorio rural que consideren la heterogeneidad paisajística del Partido y los SE identificados como prioritarios en la planificación. Los compartimentos de Serranías y Llanura distal destacan por su vulnerabilidad para la provisión de SE de regulación y soporte debido a las marcadas tasas de avance de la agricultura en su superficie. En este contexto, la provisión de SE de abastecimiento (commodities asociados a la actividad agrícola) también resulta vulnerada.

- Si bien el presente trabajo sienta las bases para la puesta en marcha de acciones de ordenamiento ambiental se remarca, por un lado, la necesidad de realizar estudios que den cuenta de los impactos ambientales y los SE más afectados asociados a cada compartimento. Por otro lado, resulta necesaria la valoración económica intrínseca de SE de regulación y culturales involucrados de modo tal que su inclusión como variables en la toma de decisiones resulte factible.

\section{Referencias Bibliográficas}

AGUILAR ARIAS, H.; MORA ZAMORA, R.; VARGAS BOLAÑOS, C. Metodología para la corrección atmosférica de imágenes Aster, Rapideye, Spot 2 y Landsat 8 con el módulo Flash del software Envi. Revista Geográfica de América Central, 2(53), 39-59, 2014.

BALVANERA, P.; COTLER, H. Acercamiento al estudio de los servicios ecosistémicos. Gaceta Ecológica 84-85: 8-15 (Julio-Diciembre), 2009. Disponible en: 〈http://vifww.redalyc.org/articulo.oa?id=53908502>.

BUREL, F.; BAUDRY, J. Ecología del paisaje: conceptos, métodos y aplicaciones. Mundi Prensa Libros SA, 2002. 


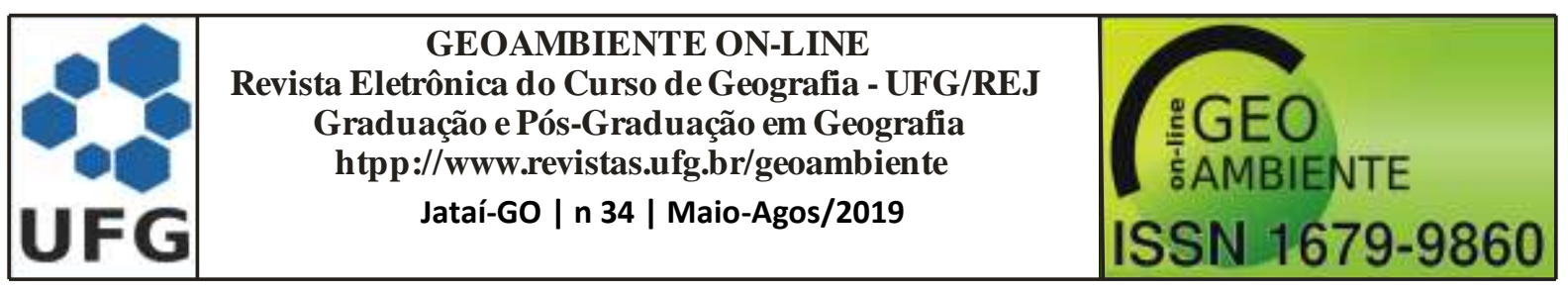

CHANDER, G.; MARKHAM, B.; BARSI, J.A. Revised Landsat-5 thematic mapper radiometric calibration. IEEE Geoscience and remote sensing letters, 4(3), 490-494, 2007. Disponible en: 〈http: 10.1109/LGRS.2007.898285>.

CLIMATE PREDICTION CENTER. 2018. National Oceanic \& Atmospheric Administration (NOAA), National Weather Service. Disponible en: $\leq \mathrm{http}$ : cpc.ncep.noaa.gov/products/precip/CWl ink/ MJO/enso.shtml>.

DE GROOT, R. S.; ALKEMADE, R.; BRAAT, L.; HEIN, L.; WILLEMEN, L. Challenges in integrating the concept of ecosystem services and values in landscape planning, management and decision making. Ecological complexity, 7(3), 260-272, 2010. Disponible en: <https://doi.org/10.1016/j.ecocom.2009.10.006>.

DUARTE, C. M.; ALONSO, S.; BENITO, G.; DACHS, J.; MONTES, C.; PARDO BUENDÍA, M.; VALLADARES, F. Cambio Global. Impacto de la actividad humana sobre el sistema Tierra. Ed. CSIC. Consejo superior de investigaciones científicas. Colección divulgación, 3. 167 p, 2006. ISBN: 978-84-00-08452-3.

EASTMAN, J.R. IDRISI Kilimanjaro, Guía para SIG y Procesamiento de Imágenes. Clark Labs Clark University, Worcester, MA, USA, 2004.

FERNÁNDEZ, G.; RAMOS, A. G. El crecimiento urbano de Tandil: ¿modelo territorial de la ciudad difusa? Geográfica digital, 10(20), 1-12, 2017. Disponible en: 〈http://dx.doi.org/10.30972/geo.10202201>.

FOOD AND AGRICULTURE ORGANIZATION OF THE UNITED NATIONS (FAO). 2005. Global Forest Resources Assessment 2005 - Progress towards sustainable forest management Food and Agriculture. Roma. Organization of the United Nations.

INDEC .1991. Censo Nacional de Población, Hogares y Viviendas 1991. Disponible en: 〈http: redatam.indec.gob.ar>.

INDEC. 2010. Censo Nacional de Población, Hogares y Viviendas 2010. Disponible en: 〈http: redatam.indec.gob.ar>.

INPE. 2017. Instituto Nacional de Pesquisas Espaciais. Ministério da Ciência, Tecnologia, Comunicações e Inovações de Brasil.

LAMBIN, E. F.; MEYFROIDT, P. Land use transitions: socio-ecological feedback versus socio-economic change. Land use policy, 27(2), 198-118, 2010. Disponible en: $\leq$ https://doi.org/10.1016/j.landusepol.2009.09.003 >. 


\begin{tabular}{|c|c|c|}
\hline & $\begin{array}{c}\text { GEOAMBIENTE ON-LINE } \\
\text { Revista Eletrônica do Curso de Geografia - UFG/REJ } \\
\text { Graduação e Pós-Graduação em Geografia } \\
\text { htpp://www.revistas.ufg.br/geoambiente } \\
\text { Jataí-Go | n } 34 \text { | Maio-Agos/2019 }\end{array}$ & $\begin{array}{c}\text { GEO } \\
\text { GF }\end{array}$ \\
\hline
\end{tabular}

LILLESAND, T.; KIEFER, R.W.; CHIPMAN, J. Remote sensing and image interpretation. John Wiley \& Sons. pp. 567, 2014.

MANUEL-NAVARRETE, D. Análisis sistémico de la agriculturización en la pampa húmeda argentina y sus consecuencias en regiones extrapampeanas: sostenibilidad, brechas de conocimiento e integración de políticas, (Vol. 118). United Nations Publications, 2006.

MARTÍN-LÓPEZ, B.; MONTES, C. Biodiversidad y servicios de los ecosistemas. Observatorio de la Sostenibilidad en España (OSE), 444-465, 2011.

MILLENNIUM ECOSYSTEM ASSESSMENT (MEA). Ecosystems and human wellbeing. Island Press, Washington, D.C., USA, 2005.

Ministerio DE AGROINDUSTRIA. Portal de Datos Abiertos del Ministerio de Agroindustria, 2018. Disponible en: $\leq$ https://www.agroindustria.gob.ar/datosabiertos/>.

NOGAR, A. G., NOGAR, M. L. \& JACINTO, G. Redes de poder, deslocalización y cambios en los usos productivos rurales pampeanos: El caso de Tandil. Pampa (Santa Fe), (15), 31-46, 2017. Disponible en: <http://www.scielo.org.ar/scielo.php?script=sci_arttext\&pid=S2314$\underline{2082017000100002 \& \operatorname{lng}=e s \& t \ln g=e s>}$.

PARUElO, J. M.; GUERSCHMAN, J. P.; PIÑEIRO, G.; JOBBAGY, E. G.; VERÓN, S. R.; BALDI, G.; BAEZA, S. Cambios en el uso de la tierra en Argentina y Uruguay: marcos conceptuales para su análisis. Agrociencia, 10(2), 47-61, 2006.

PARUELO, J.M. Capítulo 5. Valoración de servicios ecosistémicos y planificación del uso del territorio ¿Es necesario hablar de dinero? En: Jobbágy, E. G., Paruelo, J. M., \& Laterra, P. (eds.), Valoración de servicios ecosistémicos: conceptos, herramientas y aplicaciones para el ordenamiento territorial, pp. 121-137. INTA, Buenos Aires, Argentina, 2011.

PENGUE, W. Cambios y escenarios en la agricultura argentina del Siglo XXI. Buenos Aires: GEPAMA, 2014.2 Disponible en: <https://www.researchgate.net/profile/Walter_Pengue/publication/273058846>.

SÁNCHEZ, R.; MATTUS, G.; ZULAICA, L. Compartimentación ecológica y ambiental del partido de Tandil (Provincia de Buenos Aires). Congreso Ambiental, 99, 338-346, 1999.

SÁNCHEZ, R.; ZULAICA, L. Ordenamiento morfoedáfico de los sistemas ecológicos paisajísticos del partido de Tandil (Provincia de Buenos Aires). Contribuciones Científicas (Sociedad Argentina de Estudios Geográficos, 63, 387-402, 2002. 


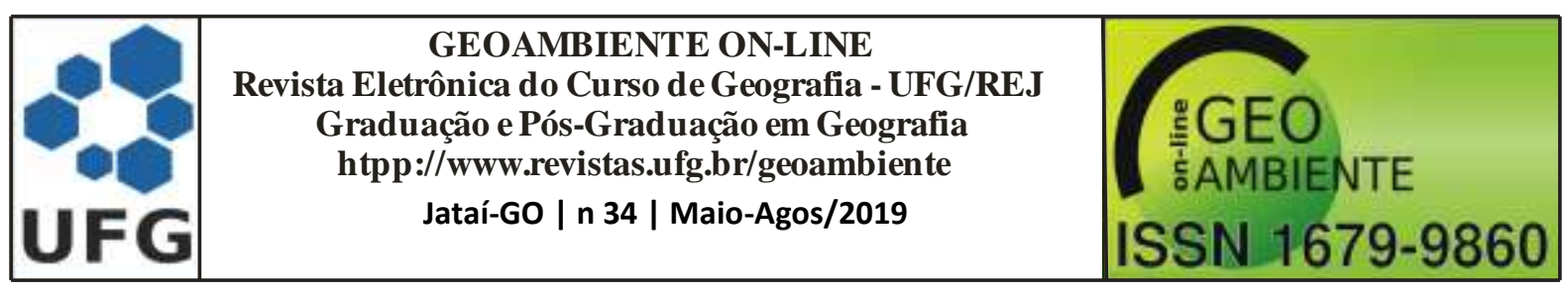

SATORRE, E.; BERT, F. Agricultura por ambientes: Conceptos para su incorporación eficaz al manejo de nuestros campos. Revista Cultivar decisiones, 13, 5, 2014.

SOMOZA, A.; VAZQUEZ, P.; ZULAICA, L. Implementación de Buenas Prácticas Agrícolas para la gestión ambiental rural. Revista RIA, Revista de Investigaciones Agropecuarias, 44(3), 2018.

VAZQUEZ, P.; ZULAICA, L. Transformaciones agroproductivas e indicadores de sustentabilidad en el Partido de Tandil (Provincia de Buenos Aires) durante los periodos 1988-2002 y 2002-2010. Campo-Território: revista de Geografía Agraria, 7(13), 5-39, 2012.

VAZQUEZ, P.; VIGNOLLES, M. Establecimiento agroproductivo ecologico vs. agricultura convencional: Partido de Tandil, Provincia de Buenos Aires. Sociedade \& Natureza, 27(2), 2015. Disponible en: 〈http://dx.doi.org/10.1590/1982-451320150206>. 